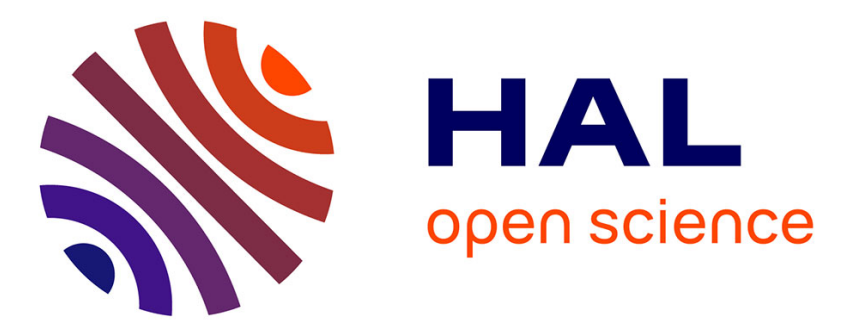

\title{
Global comparison of surface soil moisture from the ESA CCI combined product and the Orchidee Land-Surface Model
}

Nina Raoult, Bertr Delorme, Vladislav Bastrikov, Catherine Ottlé, Philippe Peylin

\section{To cite this version:}

Nina Raoult, Bertr Delorme, Vladislav Bastrikov, Catherine Ottlé, Philippe Peylin. Global comparison of surface soil moisture from the ESA CCI combined product and the Orchidee Land-Surface Model. IGARSS 2018 - 2018 IEEE International Geoscience and Remote Sensing Symposium, Jul 2018, Valencia, Spain. pp.3711-3714, 10.1109/IGARSS.2018.8517696 . hal-02390705

\section{HAL Id: hal-02390705 https://hal.science/hal-02390705}

Submitted on 30 Nov 2021

HAL is a multi-disciplinary open access archive for the deposit and dissemination of scientific research documents, whether they are published or not. The documents may come from teaching and research institutions in France or abroad, or from public or private research centers.
L'archive ouverte pluridisciplinaire HAL, est destinée au dépôt et à la diffusion de documents scientifiques de niveau recherche, publiés ou non, émanant des établissements d'enseignement et de recherche français ou étrangers, des laboratoires publics ou privés.

\section{(ㄷ)(1) $\$$}

Distributed under a Creative Commons Attribution - NonCommerciall 4.0 International 


\title{
GLOBAL COMPARISON OF SURFACE SOIL MOISTURE FROM THE ESA CCI COMBINED PRODUCT AND THE ORCHIDEE LAND-SURFACE MODEL
}

\author{
Nina Raoult, Bertrand Delorme, Vladislav Bastrikov, Catherine Ottlé, and Philippe Peylin
}

\author{
Laboratoire des Sciences du Climat et de l'Environnement, Orme des Merisiers, Gif-sur-Yvette, France
}

\begin{abstract}
Surface soil moisture (SSM) controls the the energy and water transfers between soil, vegetation and atmosphere. A better representation of this variable in Land Surface Models (LSMs) could reduce significantly the uncertainties associated to future climate predictions. Thanks to its large spatio-temporal coverage, the new ESA CCI multiinstruments dataset offers a good opportunity to benchmark LSMs and improve their parametrization with data assimilation techniques. In this study, the ESA CCI surface soil moisture (SSM) combined product is confronted with the different simulated soil layers of the ORCHIDEE LSM (the continental part of the IPSL earth system model), in order to assess whether it can be used to improve the model using data assimilation.
\end{abstract}

Index Terms - surface soil moisture, land surface model, satellite data, sensing depth

\section{INTRODUCTION}

Soil moisture plays an important role in the water, carbon and energy exchanges between the land surface and the atmosphere. It is a vital variable which needs to be better understood and controlled since it links these critical cycles. In particular, due to the coupling between water and carbon cycles at the leaf level, it is a major constraint for the assimilation of carbon by the vegetation through photosynthesis. A better representation of this variable in Land Surface Models (LSMs) could significantly reduce the uncertainties associated to future climate predictions.

To improve the representation of such variables in LSMs, the model can be confronted with the observations. These observations can be measured in situ or remotely, for example, using satellites. Since soil moisture is difficult to observe at large scales due to its high spatial and temporal variability, satellite data can provide a much needed consistent global dataset. The new ESA CCI multi-instruments dataset has a large spatio-temporal coverage. This offers a good opportunity to benchmark LSMs and, through data assimilation techniques, to improve their parametrizations. When working with this product however, we must be wary of its multiconstellation nature.
Various studies have already evaluated the quality of the ESA CCI SM product at a global scale. Liu et al. (2011 [1], 2012 [2]) showed that merging active and passive products increases the number of observations while minimally changing the accuracy. The final blended product was shown to carry the relative dynamics of the original passive and active microwave retrievals. Subsequently, Dorigo et al. (2012 [3]) revealed that most of the major trends in the blended product between 1988 and 2010 were also visible in modeled and in situ measured dataset. Albergel et al. (2013 [4]) demonstrated that product performed well in capturing the annual cycle of SSM and its short-term variability by comparing it to re-analysis and in situ measurements. Loew et al. (2013 [5]) undertook the task of summarizing potential and limitations of the ESA CCI SM product for model evaluation. They mentioned its promising use for data assimilation in LSMs. Finally, Dorigo et al. (2015 [6], 2017 [7]) validated previous studies by indicating that the merged product has a similar or better quality than the individual products and that quality shows an upward trend over time by confronting it to a large number of in situ observations.

Further studies have already shown the potential of such product to study land-atmosphere-biosphere interactions ([8], [9]) and agree that assimilating together active and passive microwave observations give maximum accuracy and coverage to improve LSM ([10]). These results give encouraging prospects on the ability of the ESA CCI SM product to improve land surface modeling with data assimilation techniques.

The comparison of observations with the model output is a mandatory first step in data assimilation. This vital step allows us to firstly assess whether the physical properties in both the observations and model output are comparable, and secondly to explore their different weaknesses and errors. It is a method used to evaluate whether the observations have the ability to improve the model through assimilation or not.

When comparing the ESA CCI SM satellite data and the output from a LSM, three limitations need to be kept in mind:

- SSM variability is largely driven by precipitation and therefore the meteorological forcing data used to run the LSM might have a greater weight on the comparison scores than the parametrisation of the model itself. 
- Satellite retrievals depend heavily on surface and subsurface properties such as soil texture, humidity and vegetation. These properties lead to spatially inhomogeneous datasets.

- The sampling of satellite observations is not continuous. In addition, the ESA CCI SM product has a multi-instruments constitution where each independent dataset has been rescaled in order to be merged together. Combining different instruments from different periods adds temporal inhomogeneity to the final dataset and thus complications for model evaluations.

Some studies have already developed methodologies to compare satellite products and model outputs in order to assess their potential for assimilation ([11], [12], [13]). Few studies have taken the next step and assimilated satellite products into the model. One such study is the pioneering work of Scholze et al. (2015 [14]) where satellite soil moisture data is assimilated together with atmospheric $\mathrm{CO}_{2}$ data. They show in their study the high potential of using soil moisture data to constrain the carbon cycle.

In this study, we compare the ESA CCI SM product with the process-based global LSM ORCHIDEE (ORganising Carbon and Hydrology In Dynamic EcosystEm, [15]) highlighting the weaknesses and strengths of both of them, and assessing whether the ESA CCI SM product can be used for data assimilation. ORCHIDEE has been recently endowed with a new 11 layers hydrological model which allows to refine the representation of soil water transfers. This discretization scheme offers a unique opportunity to match as closely as possible the representative depth of the satellite and assess its effect. It also allows us to calculate the correlation of the different layers of the model with the ESA CCI SM product in order to understand the effects of the satellite signal representative depth on the comparison scores.

\section{METHODOLOGY \& RESULTS}

The ORCHIDEE land surface model ([16], [17], [15]) simulates the different processes governing water, carbon and energy fluxes coming from the biosphere. It has a high spatial resolution flexibility and a temporal resolution of 30 minutes. ORCHIDEE is ideally suited for being confronted to remotely sensed soil moisture products due to its high vertical resolution in the representation of soil moisture ([18], [19], [20]). It's recently improved hydrological scheme is resolved by the Richards equation over the first 2 meters of soil with an 11 layers discretization. The Richards equation gives a diffusion of the water front corresponding to the soil properties chosen and thus a relation between SM at different levels corresponding to these properties.

This new hydrological model of 11 soil layers consists in improving the interaction of the root profile with the soil

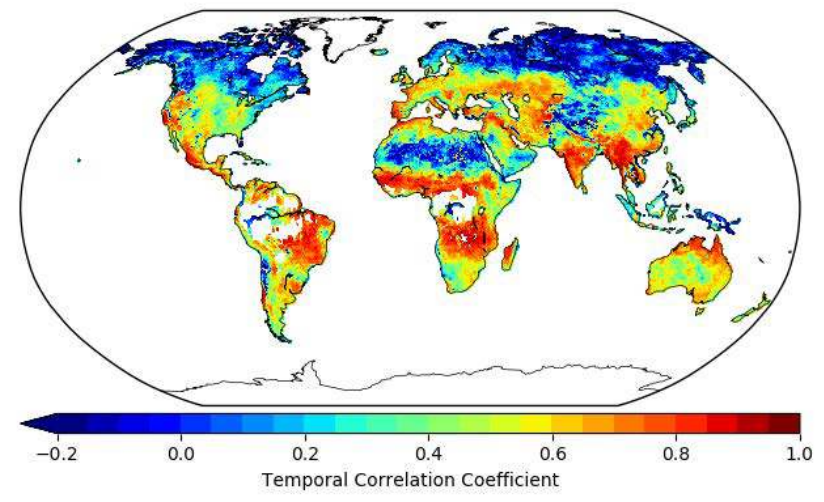

(a) Temporal correlations (using the first 4 layers of ORCHIDEE)

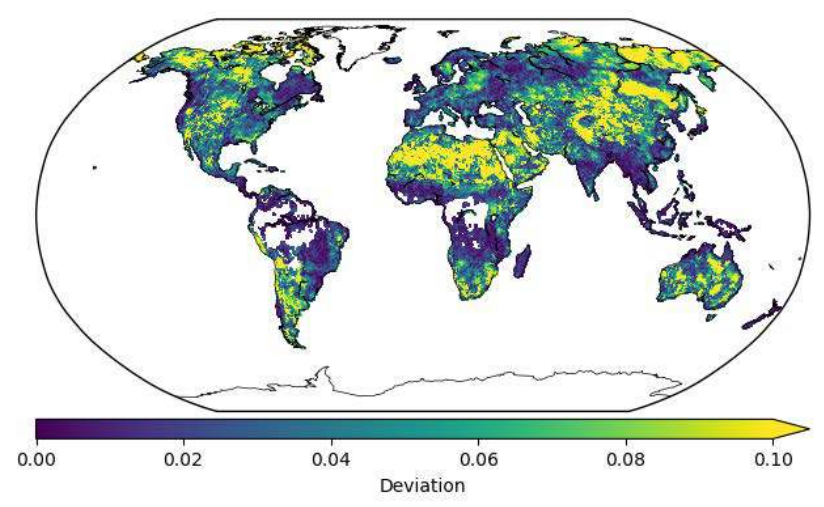

(b) Standard deviation between correlation coefficients taken at different depths in ORCHIDEE

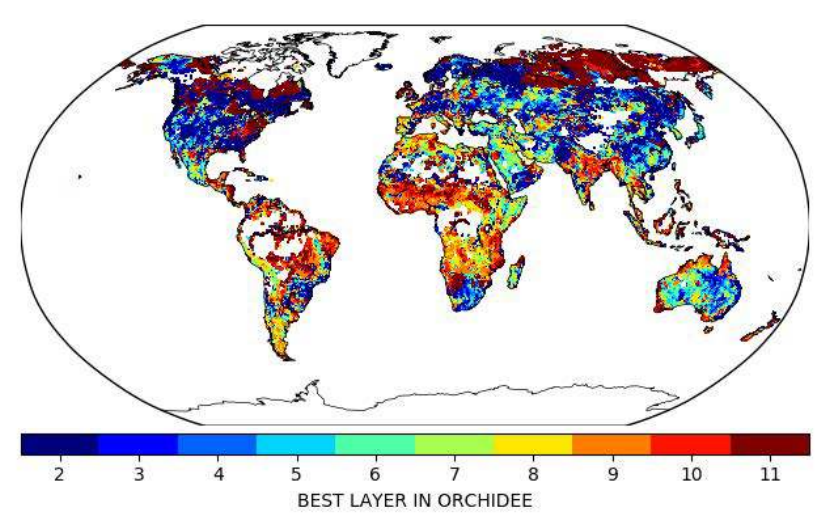

(c) Layer in ORCHIDEE offering the best agreement

Fig. 1. Results from a correlation analysis performed between ORCHIDEE and the ESA CCI product for each grid point for the period 2007-2010. 
moisture distribution at different depths and refining the representation of infiltration processes. In each grid box, three soil moisture profiles are simulated. They share the same soil texture and structure, taken from the Zobler map (Post and Zobler, http://www.daac.ornl.gov), but differ in their vegetation distribution. The 13 plant functional types represented by ORCHIDEE are distributed over the 3 columns: bare soil, low vegetation and high vegetation. As each is characterized by different root profiles, the soil moisture in each column will develop its own profile. In the analysis presented here only the grid box average soil moisture profile representative of the whole grid scale will be considered.

From the eleven soil moisture layers simulated by ORCHIDEE, the first 4 layers spanning the top $2.151 \mathrm{~cm}$ of soil are most closely related to the instruments theoretical global mean sensing depth of $2 \mathrm{~cm}$ ([21]). Therefore, it should be the closest in terms of relative dynamics of the ESA CCI SM product and is defined as the simulated SSM. The first 6 layers on the other hand span the top $9.189 \mathrm{~cm}$ of the soil which is closer the GLDAS-1-Noah model depth simulation (the GLDAS-1-Noah model is used to merge the different products used to form ESA CCI SM data). This raises the question of how to link observations to model variables, in other words how to define the observation operator which will be used in the assimilation process.

Focusing on period of relative homogeneity, as a preliminary experiment, we pursued a comparison analysis by assessing effects of depth in the model estimates. The period tested, 2007-2010, was selected due to a couple of factors. Firstly, the ESA-CCI SM product has been shown to perform best in later years when more satellites have been integrated improving spatial and temporal coverage [7]). Secondly, this period provided an overlap with the meteorological data used to drive the model.

The top plot in Figure 1 shows the correlation between the ESA CCI SM product and ORCHIDEE simulated water content integrated over the first 4 layers i.e, the soil moisture in top first $2 \mathrm{cms}$ which, as mentioned previously, should be the closest theoretically. Temporal correlations tend to be high over areas where remote sensing methods are known to be efficient. Poorer results are found over desert, mountainous and frozen areas. This may to be due to the fact that it is difficult to measure SSM by remote-sensing over these regions. Over these regions, we may be seeing the effect of mixing different sensors with different sensing depths to make up the ESA CCI product.

Areas with low correlations between the model and observations may also be due to issues with the model itself. It is possible that uncertainties due to forcing data or model structure affect the correlation scores. In this way, observations can sometimes be used to highlight structural issues in the model without even needing to go through data assimilation.

To estimate the influence of the depth chosen in ORCHIDEE on the correlation scores, Figure1b) considers the standard deviation of the correlation scores computed over all the layers of ORCHIDEE. We can see a very low variation in the correlation scores over the areas that have a strong correlation. SM is less homogeneous in the Saharan region and in central Asia. These regions correspond to the areas of low or negative correlation seeing in Figure 1a).

Finally, Figure 1c) shows the depth offering the best agreement between the ESA CCI SM data and the ORCHIDEE model. We can see for example in northern Russia, the ESA CCI SM product agrees better when large depth is used. This is an area with negative temporal correlation and a high standard deviation between the different depths. In Europe, where the temporal correlation are quite strong, a shallower depth is required. However, we must be careful making conclusions about the representative depth in areas with a low standard deviation between layers - in these cases it is likely that any depth would work.

These experiments have used the full data. Results were found to be nearly identical when using the anomalies (removing the effects of seasonality from the data). This shows that seasonality does not have an effect on representative depth of the satellite. The low variation of correlations found at the different depths of the model suggests that, at a daily scale, the dynamics between the satellite data and the model output are similar at the all levels.

Further experiments are needed to understand better the representative depth of the observations in order to determine the optimal way to assimilate the ESA CCI SM product. A next step could be to try a different metric to see whether this is more affected by the different depths.

\section{REFERENCES}

[1] Y. Y. Liu, R. M. Parinussa, W. A. Dorigo, R. A M De Jeu, W. Wagner, A. I J M. Van Dijk, M. F. McCabe, and J. P. Evans, "Developing an improved soil moisture dataset by blending passive and active microwave satellite-based retrievals," Hydrology and Earth System Sciences, vol. 15, no. 2, pp. 425-436, 2011.

[2] Y. Y. Liu, W. A. Dorigo, R. M. Parinussa, R. A. M. De Jeu, W. Wagner, M. F. McCabe, J. P. Evans, and A. I J M Van Dijk, "Trend-preserving blending of passive and active microwave soil moisture retrievals," Remote Sensing of Environment, vol. 123, no. October 2006, pp. 280-297, 2012.

[3] W. A. Dorigo, R. De Jeu, D. Chung, R. Parinussa, Y. Liu, W. Wagner, and D. Fernandez-Prieto, "Evaluating global trends (1988-2010) in harmonized multisatellite surface soil moisture," Geophysical Research Letters, vol. 39, no. 17, pp. 3-9, 2012.

[4] C. Albergel, W. A. Dorigo, R. H. Reichle, G. Balsamo, P. de Rosnay, J. Muñoz-Sabater, L. Isaksen, R. de Jeu, 
and W. Wagner, "Skill and Global Trend Analysis of Soil Moisture from Reanalyses and Microwave Remote Sensing," Journal Of Hydrometeorology, vol. 14, pp. 1259-1277, 2013.

[5] A. Loew, T. Stacke, W. Dorigo, R. De Jeu, and S. Hagemann, "Potential and limitations of multidecadal satellite soil moisture observations for selected climate model evaluation studies," Hydrology and Earth System Sciences, vol. 17, no. 9, pp. 3523-3542, 2013.

[6] W. A. Dorigo, A. Gruber, R. A M De Jeu, W. Wagner, T. Stacke, A. Loew, C. Albergel, L. Brocca, D. Chung, R. M. Parinussa, and R. Kidd, "Evaluation of the ESA CCI soil moisture product using ground-based observations," Remote Sensing of Environment, vol. 162, pp. 380-395, 2015.

[7] W. A. Dorigo, W. Wagner, C. Albergel, F. Albrecht, G. Balsamo, L. Brocca, D. Chung, M. Ertl, M. Forkel, A. Gruber, et al., "ESA CCI Soil Moisture for improved Earth system understanding: state-of-the art and future directions," Remote Sensing of Environment, vol. 203, pp. 185-215, 2017.

[8] D.G. Miralles, A. J. Teuling, C. C. Van Heerwaarden, and J. V. de Arellano, "Mega-heatwave temperatures due to combined soil desiccation and atmospheric heat accumulation," Nature geoscience, vol. 7, no. 5, pp. 345-349, 2014.

[9] J. Barichivich, K. R. Briffa, R. Myneni, G. van der Schrier, W. A. Dorigo, C. J. Tucker, T. J. Osborn, and T. M. Melvin, "Temperature and snow-mediated moisture controls of summer photosynthetic activity in northern terrestrial ecosystems between 1982 and 2011," Remote Sensing, vol. 6, no. 2, pp. 1390-1431, 2014.

[10] C. S. Draper, R. H. Reichle, G. J. M. De Lannoy, and Q. Liu, "Assimilation of passive and active microwave soil moisture retrievals," Geophysical Research Letters, vol. 39, no. 4, pp. 1-5, 2012.

[11] C. Rüdiger, J.-C. Calvet, C. Gruhier, T. R. H. Holmes, R. de Jeu, and W. Wagner, "An Intercomparison of ERSScat and AMSR-E Soil Moisture Observations with Model Simulations over France," Journal of Hydrometeorology, vol. 10, no. 2, pp. 431-447, 2009.

[12] R. H. Reichle, R. D. Koster, P. Liu, S. Mahanama, E. G. Njoku, and M Owe, "Comparison and assimilation of global soil moisture retrievals from the Advanced Microwave Scanning Radiometer for the Earth Observing System (AMSR-E) and the Scanning Multichannel Microwave Radiometer (SMMR)," Journal of Geophysical Research Atmospheres, vol. 112, no. 9, pp. 1-14, 2007.
[13] M. Parrens, E. Zakharova, S. Lafont, J. C. Calvet, Y. Kerr, W. Wagner, and J. P. Wigneron, "Comparing soil moisture retrievals from SMOS and ASCAT over France," Hydrology and Earth System Sciences, vol. 16, no. 2, pp. 423-440, 2012.

[14] M. Scholze, T. Kaminski, W. Knorr, S. Blessing, M. Vossbeck, J.P. Grant, and K. Scipal, "Simultaneous assimilation of SMOS soil moisture and atmospheric $\mathrm{CO}_{2}$ in-situ observations to constrain the global terrestrial carbon cycle," Remote Sensing of Environment, vol. 180, pp. 334-345, 2016.

[15] G. Krinner, N. Viovy, N. de Noblet-Ducoudré, J. Ogée, Jan Polcher, P. Friedlingstein, P. Ciais, S. Sitch, and I. C. Prentice, "A dynamic global vegetation model for studies of the coupled atmosphere-biosphere system," Global Biogeochemical Cycles, vol. 19, no. 1, pp. 1-33, 2005.

[16] N. I. Ducoudré, K. Laval, and A. Perrier, "SECHIBA, a New Set of Parameterizations of the Hydrologic Exchanges at the Land-Atmosphere Interface within the LMD Atmospheric General Circulation Model," 1993.

[17] P. de Rosnay and J. Polcher, "Modelling root water uptake in a complex land surface scheme coupled to a GCM,” 1998.

[18] P. de Rosnay, M. Bruen, and J. Polcher, "Sensitivity of surfage fluxes to the number of layers in the soil model used in GCMs," Geophysical Research Letters, vol. 27, no. 20, pp. 3329-3332, 2000.

[19] P. de Rosnay, J. Polcher, M. Bruen, and K. Laval, "Impact of a physically-based soil water flow and soil-plant interaction representation for modeling large-scale land surface processes," Journal of Geophysical Research, vol. 107, pp. ACL 3 1-18, 2002.

[20] T. D’Orgeval, J. Polcher, and P. de Rosnay, “Sensitivity of the West African hydrological cycle in ORCHIDEE to infiltration processes," Hydrology and Earth System Sciences, vol. 12, no. 6, pp. 1387-1401, 2008.

[21] Soil Moisture ECV Product User Guide PUG, "ESA climate change initiative phase II soil moisture," 2016. 